\title{
Hemodynamic changes with high infusion rates of lipid emulsion. Experimental study in swine $^{1}$
}

\author{
Artur Udelsmann', Marcos De Simone Melo ${ }^{\text {II }}$ \\ DOI: http://dx.doi.org/10.1590/S0102-865020150110000001
}

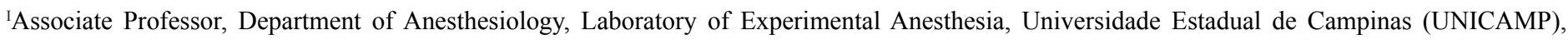
Brazil. Conception, intellectual and scientific content of the study; manuscript writing; critical revision.

IIPhD, Anesthesiologist, UNICAMP Hospital, Laboratory of Experimental Anesthesia, UNICAMP, Campinas-SP, Brazil. Acquisition and interpretation of data, critical revision.

\begin{abstract}
PURPOSE: To evaluate hemodynamic changes caused by sole intravenous infusion of lipid emulsion with doses recommended for treatment of drug-related toxicity.

METHODS: Large White pigs underwent general anesthesia, tracheal intubation was performed, and mechanical ventilation was instituted. Hemodynamic variables were recorded using invasive blood pressure and pulmonary artery catheterization. Baseline hemodynamic measurements were obtained after a 30-minute stabilization period. An intravenous bolus injection of $20 \%$ lipid emulsion at $1.5 \mathrm{ml} / \mathrm{kg}$ was administered. Additional hemodynamic measurements were made after 1 minute, followed by a continuous intravenous lipid infusion of $0.25 \mathrm{ml} / \mathrm{kg} / \mathrm{min}$. Further measurements were carried out at 10,20 and 30 minutes, when the infusion was doubled to 0.5 $\mathrm{ml} / \mathrm{kg} / \mathrm{min}$. Assessment of hemodynamic changes were then made at 40,50 and 60 minutes.

RESULTS: Lipid infusion did not influence cardiac output or heart rate, but caused an increase in arterial blood pressure, mainly pulmonary blood pressure due to increased vascular resistance. Ventricular systolic stroke work consequently increased with greater repercussions on the right ventricle.
\end{abstract}

CONCLUSION: In doses used for drug-related toxicity, lipid emulsion cause significant hemodynamic changes with hypertension, particularly in the pulmonary circulation and increase in vascular resistance, which is a factor to consider prior to use of these solutions. Key words: Fat Emulsions, Intravenous. Hemodynamics. Swine. 


\section{Introduction}

Lipid therapy for treatment of drug-related toxicity was first used in 1998 by Weinberg et al ${ }^{1}$. Those authors successfully employed lipid emulsion to combat toxicity of the local anesthetic bupivacaine in animal models. Actually, it is the same lipid used for years as a parenteral nutrition formulation. It is also the vehicle used for anesthetic agents such as propofol, a hypnotic widely used in Anesthesiology ${ }^{2}$. After local anesthetic overdose, lipid emulsions were also used to treat toxicity due to other lipophilic drugs, e.g. tricyclic antidepressants, calcium channel blockers, $\beta$-blockers, barbiturates, among others ${ }^{3}$. Several studies on the use of lipid emulsions for local anesthetic toxicity have been published, with controversial and interesting results. Mirtallo et al. ${ }^{2}$, Cave and Harvey ${ }^{4}$ considered the treatment highly efficacious, while Litz et $a l .^{5}$ have differentiated their results according to type of lipids used. Furthermore, Mazoit et al. ${ }^{6}$ have failed to find any beneficial effect! But what draws attention to this therapy is that infusion regimens recommended in parenteral nutrition range from 700$1,300 \mathrm{mg}$ of triglycerides $/ \mathrm{kg} /$ day and serum levels of triglyceride should be monitored to decrease infusion rates if triglyceride levels achieve $400 \mathrm{mg} / \mathrm{dl}$. The infusion should be interrupted, if triglyceride values reach $1,000 \mathrm{mg} / \mathrm{dl}^{7}$. Through a simple arithmetic calculation, we observed that during a 24-hour period of parenteral nutrition, as administered in clinical practice, infusion rates ranged from 0.48 to $0.9 \mathrm{mg} / \mathrm{kg} / \mathrm{min}$. In local anesthetic toxicity, medical societies recommend a bolus injection of $1.5 \mathrm{ml} / \mathrm{kg}$, followed by a continuous infusion rate of $0.25 \mathrm{ml} / \mathrm{kg} / \mathrm{min}$ of $20 \%$ lipid emulsion. The infusion rate may be increased to $0.5 \mathrm{ml} / \mathrm{kg} / \mathrm{min}$, whenever necessary. The conversion of these doses into milligrams will result in a bolus injection of $300 \mathrm{mg} / \mathrm{kg}$, followed by an infusion rate of $50 \mathrm{mg} / \mathrm{kg} / \mathrm{min}$. The intravenous infusion rate can be increased up to $100 \mathrm{mg} / \mathrm{kg} / \mathrm{min}$, which is much higher than the dose employed for parenteral nutrition ${ }^{8,9}$. In lipid treatment for local anesthetic toxicity, hemodynamic studies with various types of solutions have mainly demonstrated an increase in vascular resistance, especially pulmonary resistance ${ }^{10,11}$. However, the hemodynamic impact of high rates of lipid emulsion infusions, as recommended by medical societies, without previous knowledge of drug-related toxicity has still not been fully elucidated. The aim of this study was to confirm in our setting the hemodynamic changes in a swine model caused by sole intravenous infusion of lipid emulsion based on doses recommended for treatment of drug-related toxicity in humans.

\section{Methods}

The study was conducted at Laboratory of Experimental Anesthesia, Division of Experimental Medicine and Surgery, School of Medicine, Universidade Estadual de Campinas. Study protocol was approved by the Committee on Animal Research and Ethics. Twenty Large-White pigs of both sexes and in good general health status were used, age ranging from 2-4 months, weighing from $20-25 \mathrm{Kg}$. Animals were subjected to the following protocol:

1. The animal was fasted on the evening prior to the procedure and had free access to water.

2. On the morning of the study protocol, the animal was weighed and cannulation of an ear vein was performed. Anesthesia was induced with $25 \mathrm{mg} / \mathrm{Kg}$ of $2.5 \%$ sodium thiopental.

3. The body surface area of the animal (BSA) was calculated in square meters using the classical formula in the literature: $\mathrm{SC}=\left(9 \mathrm{X}\right.$ weight in grams $\left.{ }^{2 / 3}\right) \times 10^{-4}$, inserting the value into the parameters of a multiparametric Engstrom $\mathrm{AS} / 3{ }^{\circledR}$ monitor.

4. The animal was then intubated, connected to a pneumatic ventilator through a partial rebreathing system with $\mathrm{CO}_{2}$ absorption. Tidal volume was set at $15 \mathrm{ml} / \mathrm{Kg}$ and adequate respiratory rate was maintained to achieve $\mathrm{ETCO}_{2}$ levels between 32 - $34 \mathrm{mmHg}$, assessed by capnometry. EKG monitoring was also used in a lead similar to $\mathrm{D}_{\Pi}$.

5. Maintenance of anesthesia was performed with $1 \%$ isoflurane using fresh gas flow rates of $1 \mathrm{~L} / \mathrm{min} \mathrm{O}_{2}$. Hemoglobin saturation was maintained above $97 \%$, assessed by a probe placed on the animal tongue.

6. In an animal lower limb, the femoral artery was dissected and catheterized for continuous arterial blood pressure measurement. The homolateral femoral vein was dissected and a double-lumen Swan-Ganz 7F catheter was inserted into a pulmonary artery branch, confirmed by the morphological aspect of the pressure curve obtained. Therefore, it was possible to measure cardiac output by the thermodilution method, heart rate, mean arterial blood pressure, mean pulmonary arterial blood pressure, central venous pressure and pulmonary capillary pressure. The monitor calculated the remaining hemodynamic parameters: cardiac index, systemic and pulmonary resistance indices, left and right ventricular stroke work indices.

7. After a 30-minute stabilization period, the first hemodynamic measurements were considered baseline values $\left(\mathrm{T}_{0}\right)$.

8. In a peripheral vein, a bolus injection of $20 \%$ long- 
chain triglyceride lipid solution at $1.5 \mathrm{~mL} / \mathrm{kg}$ was given and additional hemodynamic measurement was made after 1 minute $\left(\mathrm{T}_{1}\right)$. Then an infusion with the same lipid emulsion was set at a rate of $0.25 \mathrm{ml} / \mathrm{kg} / \mathrm{min}$, taking other haemodynamic measurements at 10,20 and 30 minutes $\left(\mathrm{T}_{10}, \mathrm{~T}_{20}\right.$ and $\left.\mathrm{T}_{30}\right)$. The infusion rate was then increased to $0.5 \mathrm{ml} / \mathrm{kg} / \mathrm{min}$ and other measurements were taken at 40, 50 and 60 minutes $\left(\mathrm{T}_{40}, \mathrm{~T}_{50}\right.$ and $\left.\mathrm{T}_{60}\right)$.

9. At the end of the procedure, the anesthetized animals were sacrificed with an intravenous injection of $10 \mathrm{ml}$ of $19.1 \%$ potassium chloride.

10. To describe sample profile according to study variables, descriptive statistics of numerical variables (weight, BSA), with mean and standard deviation values were performed. ANOVA for repeated measures was used to compare longitudinal measures between time periods, followed by the contrast profile test to analyze progress between evaluations. Variables were ranktransformed due to the lack of normal distribution. The level of significance adopted by statistical tests was $5 \%$, i.e., $\mathrm{p}<0.05$.

\section{Results}

In the Table 1, the means and standard deviations of the weights and body surface areas of the animals are shown.

TABLE 1 - Weight and body surface area.

\begin{tabular}{cc}
\hline Weight \pm SD $(\mathbf{K g})$ & $\mathbf{B S A} \pm \mathbf{S D}\left(\mathbf{m}^{2}\right)$ \\
\hline $22.75 \pm 1.82$ & $0.67 \pm 0.03$ \\
\hline
\end{tabular}

\section{Mean arterial blood pressure (MAP)}

As shown in Figure 1, bolus intravenous injection of lipid solution provoked an immediate increase in MAP $\left(\mathrm{T}_{0}<\mathrm{T}_{1}\right)$. Continuous intravenous lipid infusion resulted in further increase in blood pressure, with $\mathrm{T}_{1}<\mathrm{T}_{10}$ until $\mathrm{T}_{60}$. At an intravenous infusion rate of $0.25 \mathrm{ml} / \mathrm{kg} / \mathrm{min}$, blood pressure levels continued to rise until $\mathrm{T}_{20}$. After $\mathrm{T}_{30}$ and at $0.5 \mathrm{ml} / \mathrm{kg} / \mathrm{min}$, no additional changes were observed, with $\mathrm{T}_{10}<\mathrm{T}_{20}=\mathrm{T}_{30}$ until $\mathrm{T}_{60}(\mathrm{p}<0.0001)$.

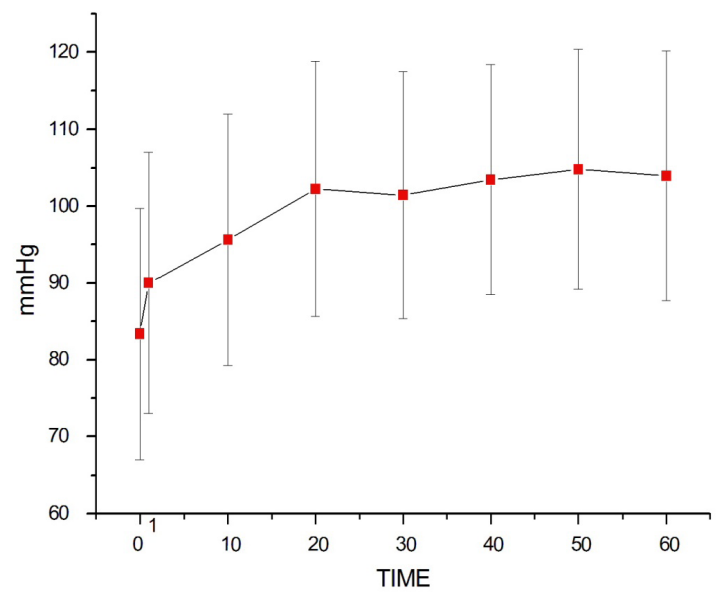

FIGURE 1 - Mean arterial blood pressure.

\section{Heart rate (HR)}

As shown in Figure 2, a bolus injection of lipid emulsion solution and both rates of lipid infusion did not cause any statistically significant changes in $\mathrm{HR}$, with $\mathrm{T}_{0}=\mathrm{T}_{1}$ until $\mathrm{T}_{60}$ $(\mathrm{p}=0.0595)$.

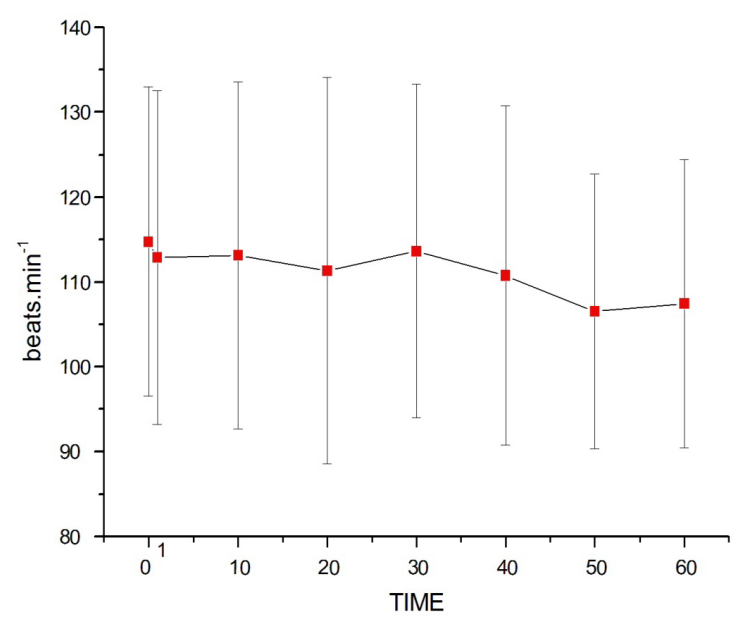

FIGURE 2 - Heart rate.

\section{Central venous pressure (CVP)}

Figure 3 demonstrates that lipid solution provoked an increase in CVP during the whole experiment $\left(\mathrm{T}_{0}<\mathrm{T}_{1}\right.$ to $\left.\mathrm{T}_{60}\right)$. Lipid emulsion infusion resulted in $\mathrm{T}_{1}<\mathrm{T}_{10}$ until $\mathrm{T}_{50}$ and $\mathrm{T}_{10}<\mathrm{T}_{20}>\mathrm{T}_{30}$ and $\mathrm{T}_{40}>\mathrm{T}_{60}(\mathrm{p}<0.0001)$. Neither infusion rates resulted in different values. 


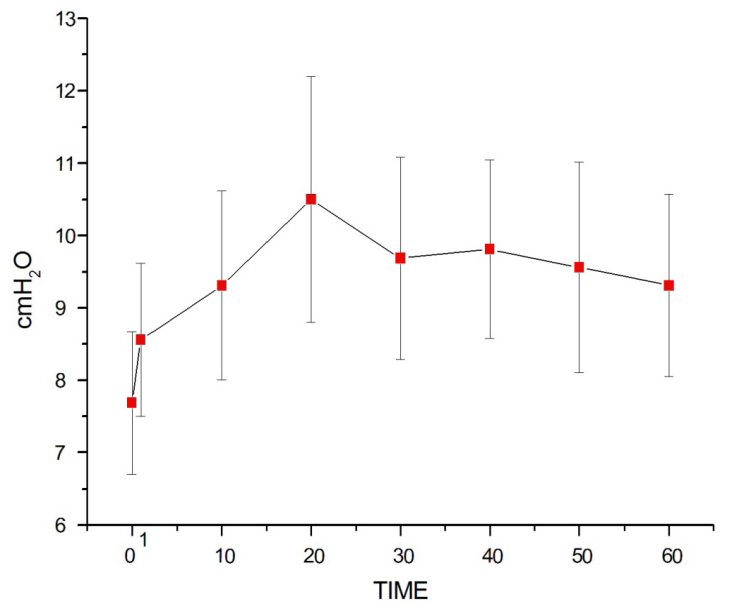

FIGURE 3 - Central venous pressure.

\section{Mean pulmonary artery pressure (MPAP)}

As shown in Figure 4, a bolus injection of lipid solution provoked an increase in MPAP, with $\mathrm{T}_{0}<\mathrm{T}_{1}$ to $\mathrm{T}_{60}$. Using continuous intravenous lipid infusion, values continued to rise, with $\mathrm{T}_{1}<\mathrm{T}_{10}$ until $\mathrm{T}_{60}$ and $\mathrm{T}_{10}<\mathrm{T}_{20}$ to $\mathrm{T}_{60}(\mathrm{p}<0.0001)$. No other differences between both infusion rates were observed.

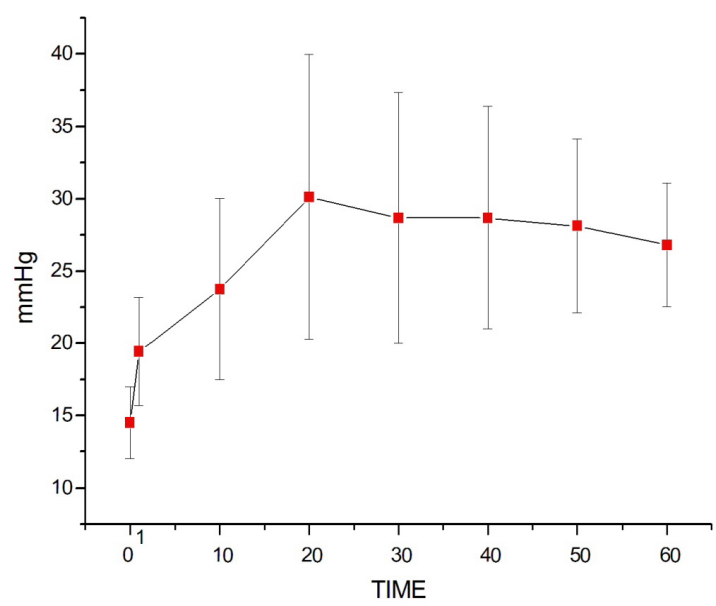

FIGURE 4 - Mean pulmonary arterial pressure.

\section{Pulmonary capillary wedge pressure (PCWP)}

Figure 5 shows that a lipid solution provoked a significant increase in PCWP during the entire experiment $\left(\mathrm{T}_{0}<\mathrm{T}_{1}\right.$ until $\left.\mathrm{T}_{60}\right)$. Lipid infusion caused progressive increase in values until $\mathrm{T}_{20}$ when they declined progressively. After $T_{50}$, values returned to levels similar to $\mathrm{T}_{1}$, in addition to $\mathrm{T}_{20}<\mathrm{T}_{60}(\mathrm{p}<0.0001)$.

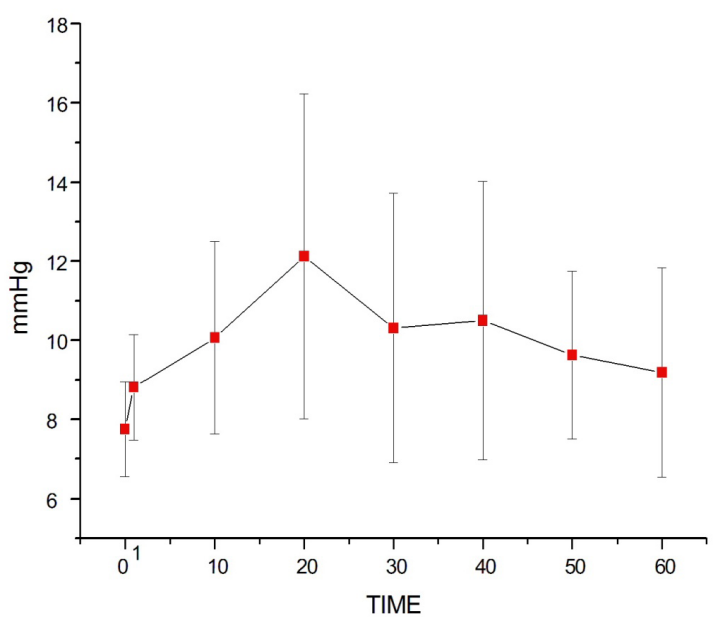

FIGURE 5 - Pulmonary capillary wedge pressure.

\section{Cardiac index (CI)}

Figure 6 shows that a bolus injection of lipid solution and continuous intravenous lipid infusion had no statistically significant impact on $\mathrm{CI}$, and $\mathrm{T}_{0}=\mathrm{T}_{1}$ until $\mathrm{T}_{60}(\mathrm{p}=0.2699)$.

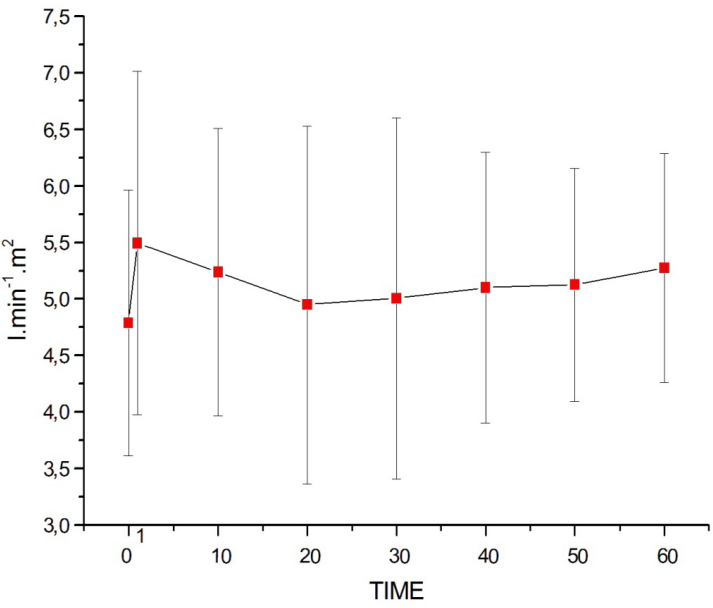

FIGURE 6 - Cardiac index.

Systemic vascular resistance index (SVRI)

Figure 7 shows that bolus injection of lipid solution had no repercussions on SVRI in $\mathrm{T}_{1}$. However, after starting lipid pump infusion, and after $\mathrm{T}_{20}$, all values were higher than at $\mathrm{T}_{0}$ and $\mathrm{T}_{1}$, in addition to $\mathrm{T}_{10}<\mathrm{T}_{20}$ until $\mathrm{T}_{50}(\mathrm{p}=0.0001)$. No differences between infusion rates were noticed. 


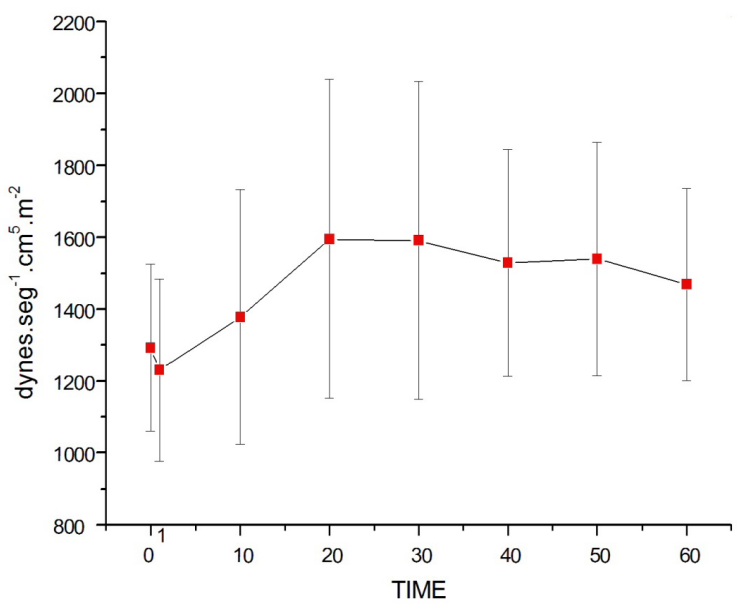

FIGURE 7 - Sistemic vascular resistance index.

\section{Pulmonary vascular resistance index (PVRI)}

On Figure 8, it is shown that both the bolus injection and the two continuous infusion rates increased PVRI, with $\mathrm{T}_{0}<\mathrm{T}_{1}<\mathrm{T}_{10}$ until $\mathrm{T}_{60}$ and infusion $\mathrm{T}_{10}<\mathrm{T}_{20}$ until $\mathrm{T}_{60}$. After $\mathrm{T}_{20}$, there was no difference between either infusion rates $(\mathrm{p}<0.0001)$.

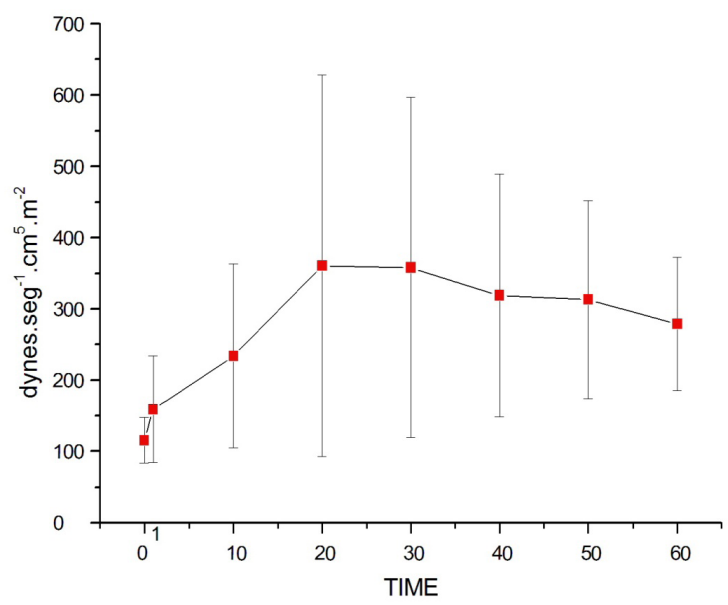

FIGURE 8 - Pulmonary vascular resistance index.

\section{Left ventricular stroke work index (LVSWI)}

Figure 9 shows that both the bolus injection and continuous lipid infusion caused a significant increase in LVSWI, with $\mathrm{T}_{0}<\mathrm{T}_{1}$ to $\mathrm{T}_{60}$. Lipid infusion of $0.5 \mathrm{ml} / \mathrm{kg} / \mathrm{min}$ resulted in $\mathrm{T}_{1}$ and $\mathrm{T}_{10}<\mathrm{T}_{50}$ and $\mathrm{T}_{60}(\mathrm{p}=0.0002)$.

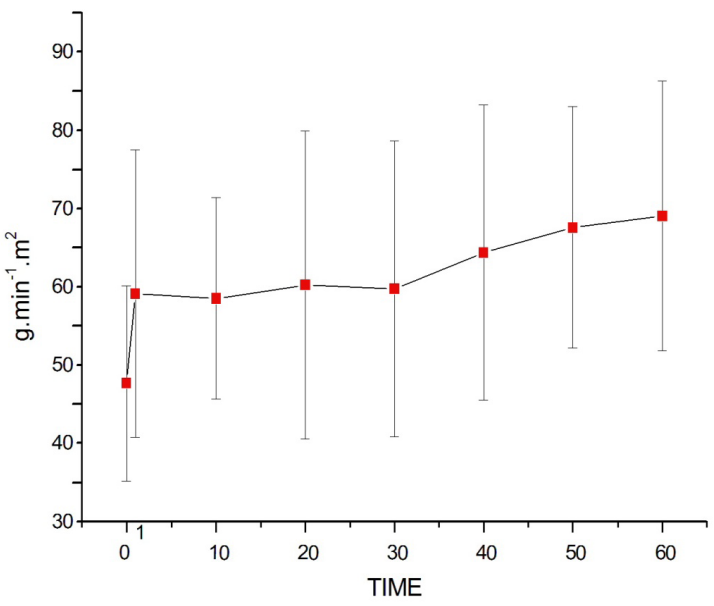

FIGURE 9 - Left ventricular stroke work index.

Right ventricular stroke work index (RVSWI)

Figure 10 shows that bolus injection and both continuous lipid infusion rates increased RVSWI values significantly, with $\mathrm{T}_{0}<\mathrm{T}_{1}$ until $\mathrm{T}_{60}$. Lipid infusion rates at $0.5 \mathrm{ml} / \mathrm{kg} / \mathrm{min}$ increased values further, with $\mathrm{T}_{1}<\mathrm{T}_{10}<\mathrm{T}_{20}$ until $\mathrm{T}_{60}$, in addition to $\mathrm{T}_{30}<\mathrm{T}_{50}$ $(\mathrm{p}<0.0001)$.

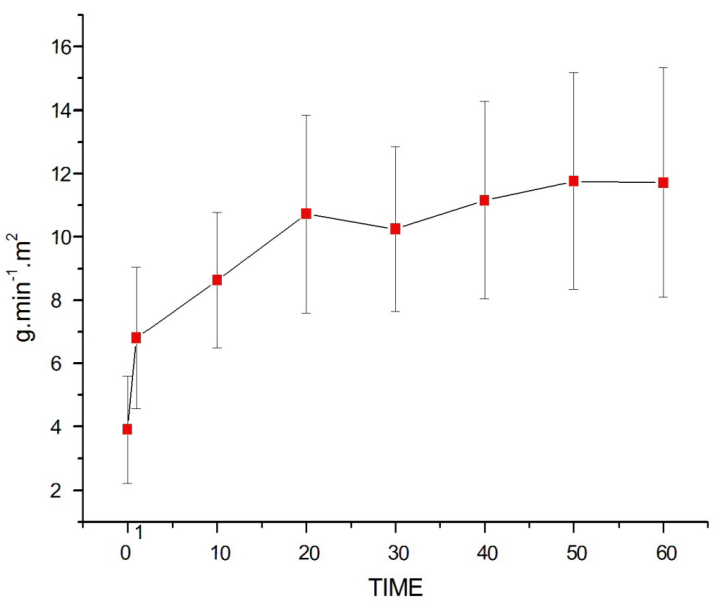

FIGURE 10 - Right ventricular stroke work index.

\section{Discussion}

In the literature, hemodynamic changes caused by lipids have contradictory results. The infusion regimens, lipid compositions and patients studied were all different, which could justify such results. Using 2 types of lipid solutions in parenteral 
nutrition at a dose of $0.12 \mathrm{~g} / \mathrm{kg} / \mathrm{h}$ for $12 \mathrm{~h}$ in individuals with acute respiratory distress syndrome, Sabater et al..$^{12}$ found no significant hemodynamic changes with both lipid solutions used. Experimental animal studies have shown a link between hypertension and plasma-nonesterified fatty acids. In piglets, arterial blood pressure and vascular resistance increased at the time of lipid infusion ${ }^{13}$. In contrast, Stojilkovic et al..$^{14}$ in healthy human volunteers using continuous intravenous lipid infusion at $0.8 \mathrm{ml} / \mathrm{m}^{2} / \mathrm{min}$ observed an increase in both systolic and diastolic arterial pressure and heart rate. According to these authors, plasma nonesterified fatty acids increase vascular response to $\mathrm{a}_{1}$-agonists and stimulate oxidative stress through protein kinase C-dependent activation. As a result, fatty acids are closely related to vascular changes with hypertension. Using a $40 \mathrm{ml} / \mathrm{h}$ lipid emulsion infusion in obese normotensive diabetics, Umpierrez et $a l .{ }^{15}$ observed an increase in arterial blood pressure, in addition to endothelial dysfunction. According to those authors, elevated lipid levels could exacerbate $\mathrm{a}_{1}$-adrenoceptor and baroceptor sensitivity. An increased rate of free fatty acids could damage endothelium-dependent vasodilation leading to activation of the sympathetic system, increasing neurovascular tonus and oxidative stress with vasoconstriction. In healthy adults receiving a lipid emulsion infusion of $150 \mathrm{mg} / \mathrm{min}$ during two hours, Kearney et $a l .{ }^{16}$ observed an increase in arterial blood pressure. However, contrary to our findings, those authors failed to notice any change in vascular resistance. Our results showed a significant increase in arterial blood pressure, both systemic and pulmonary. However, there is a particular increase in pulmonary arterial pressure, due to a significant rise in vascular resistance, since cardiac index and heart rate had no significant changes. Biventricular work indices consequently increased. Attention was once again focused on repercussions on the pulmonary circulation. Lipid therapy proved to be efficient in several situations for drug-related toxicity in doses recommended by medical societies. However, the procedure is not devoid of additional risks and haemodynamic changes can be clinically relevant.

\section{Conclusion}

High infusion rates of long-chain triglyceride lipid emulsions in pigs provoke significant haemodynamic changes with hypertension due to increased vascular resistance, mainly in the pulmonary circulation. In clinical settings, this should be considered prior to use of these solutions.

\section{References}

1. Weinberg GL, VadeBoncouer T, Ramaraju GA, Garcia-Amaro MF, Cwik MJ. Pretreatment or resuscitation with a lipid infusion shifts the dose-reponse to bupivacaine-induced asystole in rats. Anesthesiology. 1998 Apr;88(4):1071-5. doi: 10.1097/00000542199804000-00028.

2. Mirtallo JM, Dasta JF, Kleinschmidt KC, Varon J. State of the art review: Intravenous fat emulsions: current applications, safety profile, and clinical implications. Ann Pharmacother. 2010 Apr;44(4):688-700. doi: 10.1345/aph.1M626.

3. Kiberd MB, Minor SF. Lipid therapy for the treatment of a refractory amitriptilyne overdose. CJEM. 2012 May;14(3):193-7. doi: 10.2310/8000.2011.110486.

4. Cave G, Harvey M. Intravenous lipid emulsion as antidote beyond local anesthetic toxicity: a systematic review. Acad Emerg Med. 2009 Sep;16(9):815-24. doi: 10.1111/j.1553-2712.2009.00499.x

5. Litz RJ, Roessel T, Heller AR, Stehr SN. Reversal of central nervous system and cardiac toxicity following local anesthetic intoxication by lipid emulsion injection. Anesth Analg. 2008 May;106(5):15757. doi: 10.1213/ane.0b013e3181683dd7

6. Mazoit JX, Le Guen R, Beloeil H, Benhamou D. Binding of longlasting local anesthetics to lipid emulsion. Anesthesiology. 2009 Feb;110(2):380-6. doi: 10.1097/ALN.0b013e318194b252.

7. Hicks SD, Salcido DD, Logue ES, Suffoletto BP, Empey PE, Poloyac SM, Miller DR, Callaway CW, Menegazzi JJ. Lipid emulsion combined with epinephrine and vasopressin does not improve survival in a swine modelo of bupivacaine-induced cardiac arrest. Anesthesiology. 2009 Jul;111(1):138-46. doi: 10.1097/ ALN.0b013e3181a4c6d7.

8. Adolph M, Heller AR, Koch T, Koletzko B, Kreymann KG, Krohn K, Pscheidl E, Senkal M. Lipid emulsions - Guidelines on parenteral nutrition. Ger Med Sci. 2009 Nov 18;7:Doc22. doi: 10.3205/000081.

9. Neal JM, Bernards CM, Butterworth JF 4th, Di Gregorio G, Drasner K, Hejtmanek MR, Mulroy MF, Rosenquist RW, Weinberg GL. ASRA practice advisory on local anesthetic systemic toxicity. Reg Anesth Pain Med. 2010 Mar-Apr;35(2):152-61. doi: 10.1097/ AAP.0b013e3181d22fcd.

10. Melo MDS, Bonfim MR, Dreyer E, Bassanezi BSB, Udelsmann A. Hemodynamic changes in lipid emulsion therapy (SMOFlipid) for bupivacaine toxicity in swines. Acta Cir Bras. 2012 Apr;27(4):31824. doi: 10.1590/S0102-86502012000400007.

11. Bonfim MR, Melo MS, Dreyer E, Borsoi LFA, Oliveira TG, Udelsmann A. Lipid therapy with two agents in ropivacaine-induced toxicity: experimental study in swine. Rev Bras Anestesiol. 2012 Sep-Oct;62(5):685-95. doi: 10.1016/S0034-7094(12)70167-8.

12. Sabater J, Masclans JR, Sacanell J, Chacon P, Sabin P, Planas M. Effects on hemodynamics and gas exchange of omega-3 fatty acidenriched lipid emulsion in acute respiratory distress syndrome (ARDS): a prospective, randomized, double-blind, parallel group study. Lipids Health Dis. 2008 Oct 23;7:39. doi: 10.1186/1476511X-7-39.

13. Bülow J, Madsen J, Højgaard L. Reversibility of the effects on local circulation of high lipid concentrations in blood. Scand J Clin Lab Invest. 1990 May;50(3):291-6. doi: 10.3109/00365519009091581.

14. Stojiljkovic MP, Zhang D, Lopes HF, Lee CG, Goodfriend TL, Egan BM. Hemodynamic effects of lipids in humans. Am J Physiol Regul Integr Comp Physiol. 2001 Jun;280(6):R1674-9. PMID: 11353670.

15. Umpierrez GE, Smiley D, Robalino G, Peng L, Kitabchi AE, Khan B, Le A, Quyyumi A, Brown V, Phillips LS. Intravenous intralipidinduced blood pressure elevation and endothelial dysfunction in obese African-Americans with type 2 diabetes. J Clin Endocrinol Metab. 2009 Feb;94(2):609-14. doi: 10.1210/jc.2008-1590. 
Udelsmann A, De Simone Melo M

16. Kearney MT, Chowienczyk PJ, Brett SE, Sutcliffe A, Ritter JM, Shah AM. Acute haemodynamic effects of lipolysis-induced increase of free fatty acids in healthy men. Clin Sci (Lond). 2002 May;102(5):495-500. doi: 10.1042/CS20010248.

\section{Correspondence:}

Artur Udelsmann

Avenida Professor Atílio Martini, 213

13083-830 Campinas - SP Brasil

au1849@gmail.com

Received: July 16, 2015

Review: Sep 18, 2015

Accepted: Oct 19, 2015

Conflict of interest: none

Financial source: UNICAMP

${ }^{1}$ Research performed at Laboratory of Experimental Anesthesia, Universidade Estadual de Campinas (UNICAMP), Sao Paulo, Brazil. 